\title{
EDITORIAL
}

\section{Implantação da CBHPM quinta edição}

\author{
*Guilherme Benjamin Brandão Pitta
}

Os Fóruns das regionais da Sociedade Brasileira de Angiologia e de Cirurgia Vascular (SBACV) e o Workshop de Defesa Profissional sobre procedimentos médicos, diretrizes, Troca de Informações em Saúde Suplementar (TISS), Terminologia Unificada de Saúde Suplementar (TUSS) ${ }^{1}$ e resolução do Conselho Federal de Medicina (CFM) sobre auditoria médica e novo Código de Ética Médica concluíram ser importante, para nossa especialidade, a implantação da Classificação Brasileira Hierarquizada de Procedimentos Médicos $(\mathrm{CBHPM})^{2}$. As razões são as seguintes:

1. a CBHPM representa o parâmetro mínimo de remuneração dos honorários médicos recomendado pelo $\mathrm{CFM}^{3}$ e estabelecido pela Associação Médica Brasileira (AMB), representando um grande avanço no sentido da valorização da atividade médica;

2. a Agência Nacional de Saúde (ANS) ${ }^{1}$ adotou o padrão de códigos da CBHPM para a saúde suplementar (convênios, cooperativas, seguro saúde e planos de saúde privados), ou seja, as operadoras de planos de saúde privados terão de adotar o TUSS ${ }^{1}$ como referência, incorporando mais de 80\% dos códigos da CBHPM quinta edição;

3. os valores de honorários praticados nos procedimentos serão oportunamente negociados por uma comissão mista (AMB, CFM e sociedades) com as operadoras de plano privado de saúde, tendo como base a CBHPM; não é mais considerado como cartel utilizar a CBHPM como parâmetro para atuação na saúde suplementar, de acordo com a decisão da quinta vara do Tribunal Federal de Justiça ${ }^{4}$;

4. as diretrizes da $\mathrm{AMB} / \mathrm{SBACV}$ são muito importantes para a pesquisa ${ }^{5,6} \mathrm{e}$ para $\mathrm{o}$ apoio às decisões de procedimentos que são propostos e colocados na CBHPM quinta edição.

Todos os presidentes de regionais deverão apresentar os resultados de discussões locais desse movimento com os associados e na reunião do Colegiado de Presidentes no Encontro Norte-Nordeste de Angiologia e Cirurgia Vascular em Salvador, onde será decidida a posição da SBACV quanto à adesão, junto com sociedades de especialidades de todo o Brasil na "Implantação plena da CBHPM quinta edição".

É importante que todos participem e se conscientizem da importância desse movimento, considerando que o nãoenvolvimento de colegas médicos nos movimentos coletivos, com desrespeito às decisões de classe, pode ser considerado infração ética pelo Conselho Regional de Medicina (CRM), de acordo com o novo Código de Ética Médica ${ }^{3}$

\section{Referências}

1. Terminologia Unificada de a Saúde Suplementar (TUSS). 2008. http://www.amb.org.br/teste/tuss.html. Acesso em: 7 out. 2010.

2. Classificação Brasileira Hierarquizada de Procedimentos Médicos - quinta edição. 2008. http://www.amb.org.br/teste/cbhpm/ cbhpm_5a_ed.pdf. Acesso em: 7 out. 2010.

3. Código de Ética Médica. 2009. http://www.amb.org.br/teste/downloads/novocodigoetica.pdf. Acesso em: 7 out. 2010.

4. Associação Médica Brasileira. "TRF considera legítimo o uso de tabela de honorários para cobrança de serviços médicos". 2010. http://www.amb.org.br/teste/index.php?acao=mostra noticia\&id=6273. Acesso em: 18 out. 2010.

5. Pitta GBB, Roque FP, Pitta MR. O sexteto mágico da pesquisa clínica. Rev Bras Cir Cardiovasc. 2009;24(2):113-115.

6. Pitta GBB, Castro AA. A pesquisa científica. I Vasc Bras. 2006;5(4):243-4.

* Presidente da Sociedade Brasileira de Angiologia e de Cirurgia Vascular. 